\title{
Effects of Input Voltage on Flow Separation Control for Low-Pressure Turbine at Low Reynolds Number by Plasma Actuators
}

\author{
Takayuki Matsunuma and Takehiko Segawa \\ Turbomachinery Group, Energy Technology Research Institute, National Institute of Advanced Industrial \\ Science and Technology (AIST), 1-2-1 Namiki, Ibaraki, Tsukuba 3058564, Japan \\ Correspondence should be addressed to Takayuki Matsunuma, t-matsunuma@aist.go.jp
}

Received 23 July 2012; Revised 2 November 2012; Accepted 7 November 2012

Academic Editor: N. Sitaram

Copyright (C 2012 T. Matsunuma and T. Segawa. This is an open access article distributed under the Creative Commons Attribution License, which permits unrestricted use, distribution, and reproduction in any medium, provided the original work is properly cited.

\begin{abstract}
Active flow control using dielectric barrier discharge (DBD) plasma actuators was investigated to reattach the simulated boundary layer separation on the suction surface of a turbine blade at low Reynolds number, $\operatorname{Re}=1.7 \times 10^{4}$. The flow separation is induced on a curved plate installed in the test section of a low-speed wind tunnel. Particle image velocimetry (PIV) was used to obtain instantaneous and time-averaged two-dimensional velocity measurements. The amplitude of input voltage for the plasma actuator was varied from $\pm 2.0 \mathrm{kV}$ to $\pm 2.8 \mathrm{kV}$. The separated flow reattached on the curved wall when the input voltage was $\pm 2.4 \mathrm{kV}$ and above. The displacement thickness of the boundary layer near the trailing edge decreased by $20 \%$ at $\pm 2.0 \mathrm{kV}$. The displacement thickness was suddenly reduced as much as $56 \%$ at $\pm 2.2 \mathrm{kV}$, and it was reduced gradually from $\pm 2.4 \mathrm{kV}$ to $\pm 2.8 \mathrm{kV}$ (77\% reduction). The total pressure loss coefficient, estimated from the boundary layer displacement thickness and momentum thickness, was 0.172 at the baseline (actuator off) condition. The total pressure loss was reduced to 0.107 (38\% reduction) at $\pm 2.2 \mathrm{kV}$ and 0.078 ( $55 \%$ reduction) at $\pm 2.8 \mathrm{kV}$.
\end{abstract}

\section{Introduction}

Blade Reynolds numbers for the low-pressure turbine of small- and medium-sized gas turbines for aircraft propulsion can drop to below $2.5 \times 10^{4}$ at high altitudes, where the air density is low [1]. At these low Reynolds numbers, the boundary layer is dominated by laminar flow and is susceptible to flow separation and strong secondary vortices that develop into increased losses, leading to reduced performance.

Newly developed high-efficiency small-scale gas turbines for industrial power generation also encounter the low Reynolds number problem because of the increased viscosity caused by high turbine inlet temperatures and miniaturization of the cascade [2]. Several studies focusing on the aerodynamics of turbine cascades at low Reynolds numbers have been published [3-7].
Different passive and active flow control techniques have been developed to increase the efficiency of the turbine blade at low Reynolds numbers [8]. Passive control devices, such as dimples and fixed turbulators, are traditional approaches to trigger transition and induce reattachment, but create undesirable drag at high Reynolds number. Active control devices can be employed only when needed. Vortex generating jets (VGJs) and plasma actuators are prominent subjects of recent research in active flow control.

The application of dielectric barrier discharge (DBD) plasma actuator was demonstrated by Roth et al. [9] in 1998 and has been developed over the last decade from fundamental studies to a wide range of applications [10].

Figure 1 shows a simple schematic configuration of a DBD plasma actuator. The DBD plasma actuator consists of a dielectric layer sandwiched between top and bottom electrodes. Applying high voltages at high frequencies 


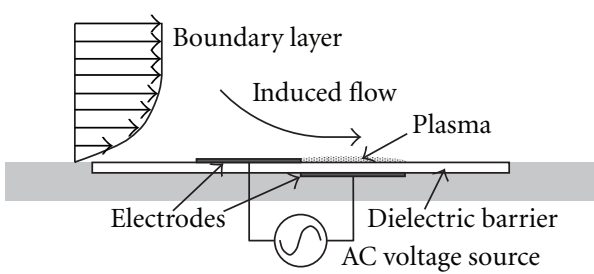

FIgURE 1: Schematics of plasma actuator.

(approximately $1 \mathrm{kHz} \sim 50 \mathrm{kHz}$ ) between the top and bottom electrodes forms a layer of glow discharge plasma across the dielectric surface. This induces a tangential air jet with a strong horizontal velocity component. It is known that the direction of the resultant tangential jet is constant and independent of which electrode the voltage is applied to, and independent of the polarity of the applied voltage [11].

DBD plasma actuators have also been used in a number of low-pressure turbine separation control studies [12-18]. In order to distinguish this work from these prior studies, this paper focused on the presentation of detailed PIV flow data and accompanying analysis at various input voltage of the plasma actuator.

The objective of this study is to investigate the most effective active flow control operation of DBD plasma actuators by simplified experiments. The experimental results in this study will be used as the fundamental data for considering the application of DBD plasma actuators for the annular turbine wind tunnel with a single-stage axial-flow turbine $[19,20]$. This paper presents the results of particle image velocimetry (PIV) measurement to understand the flow mechanisms and the effect of different amplitude of the plasma actuator input voltage.

\section{Experimental Facility and Method}

Figure 2 shows the measurement system. The wind tunnel is a low-speed, open-circuit, blower-type facility with $305 \mathrm{~mm} \times 85 \mathrm{~mm} \times 65 \mathrm{~mm}$ test section.

A curved wall plate (streamwise length $L=100 \mathrm{~mm}$ ) was installed in the test section of the wind tunnel in order to simulate the separated flow on the suction surface of a turbine blade. Figure 3 shows the geometry and the design-surface velocity distribution, derived from an inviscid calculation, at the midspan of the corresponding turbine rotor blade in the annular turbine wind tunnel in AIST $[19,20]$. Table 1 shows the nondimensional parameters of the corresponding turbine rotor midspan. The shape of the curved wall was designed using a simple one-dimensional continuity argument to match the design surface velocity and pressure distributions of the corresponding turbine blade. A plasma actuator was mounted at the front of the adverse pressure gradient region (deceleration region) on the curved wall.

Particle image velocimetry (PIV) was employed to quantify the behavior of the flow field around the curved wall. The laser was a $25 \mathrm{~mJ} /$ pulse, double-pulse Nd-YAG laser (MiniLase II, $20 \mathrm{~Hz}$, New Wave Research Co. Ltd.). Atomized

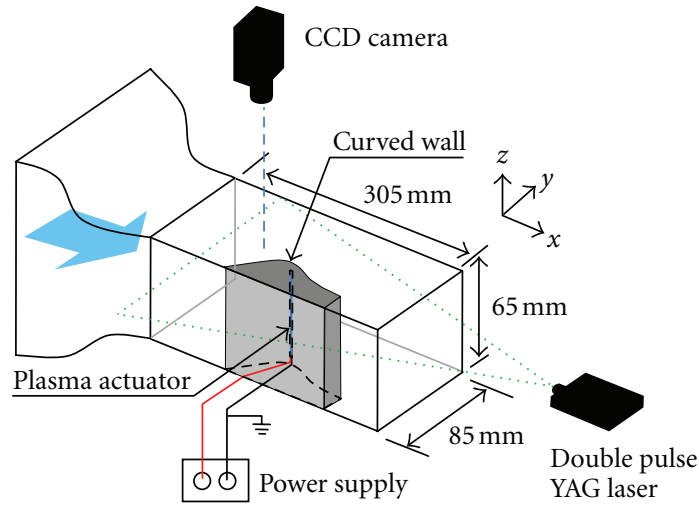

FIGURE 2: Measurement system.

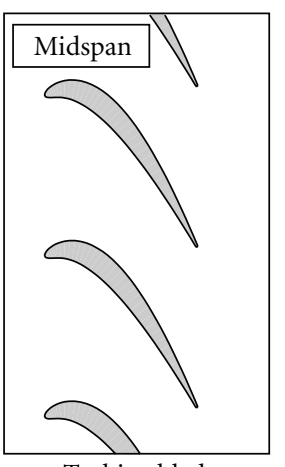

Turbine blade

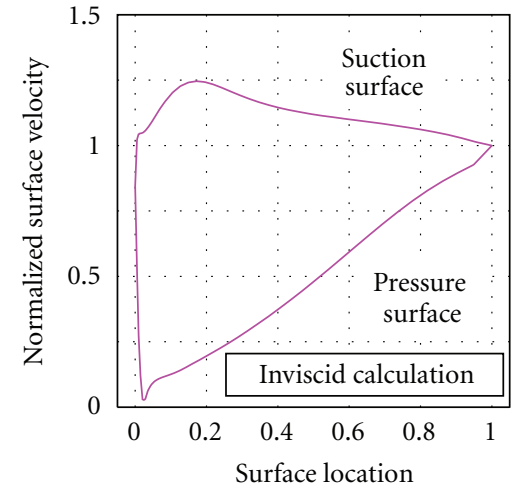

FIGURE 3: Corresponding turbine rotor.

TABle 1: Nondimensional parameters of corresponding turbine rotor (midspan).

\begin{tabular}{lcc}
\hline Inlet blade angle & $\beta_{1}$ & $21.8 \mathrm{deg}$ \\
Exit blade angle & $\beta_{2}$ & $63.4 \mathrm{deg}$ \\
Blade turning angle & $\beta_{1}+\beta_{2}$ & $85.2 \mathrm{deg}$ \\
Stagger angle & $\xi$ & $47.6 \mathrm{deg}$ \\
Diffusion factor & $D$ & 0.198 \\
Solidity (chord/pitch) & $C / S$ & 1.42 \\
Trailing edge thickness/passage width & $t / w$ & 0.032 \\
\hline
\end{tabular}

Dioctyl sebacate (DOS) oil with a mean particle diameter of $1 \mu \mathrm{m}$ was injected upstream of the test section via a pressurized oil chamber. Image pairs were taken by a camera (PIV CAM 13-8, TSI Inc.), which has $1,280 \times 1,024$ pixel resolution. TSI software calculated the velocity vectors from the peak correlation of groups of particles between frames, using conventional cross-correlation algorithms on a $32 \times$ 32 pixel grid. In order to calculate the averaged velocity distributions, 50 instantaneous velocity distributions were measured at each experimental condition in this study. It should be noted that the PIV data in the vicinity of the plasma actuator possesses lower reliability than that in the main flow, due to the laser reflections from the top electrode of the plasma actuator, the large velocity gradients across 
the induced jet, and the possibility that the seeding particles are influenced by the electric field $[21,22]$.

Figure 4 shows the test section geometry and PIV measurement grids. In these experiments, the rotating speed of the wind tunnel blower was kept constant. The streamwise velocity of the main flow near the trailing edge $(x=100 \mathrm{~mm})$ was almost constant, $U_{x \text {, main flow }} \approx 2.25 \mathrm{~m} / \mathrm{s}$, for each input voltage condition, as shown later in Figure 11. Therefore, the Reynolds number based on the streamwise length of the curved wall, $L$, and the streamwise velocity of the main flow near the trailing edge, $U_{x}$, was $\operatorname{Re}=1.7 \times 10^{4}$.

The edge of the top electrode of the plasma actuator, where the surface plasma is formed, was located at $x=$ $30.6 \mathrm{~mm}$ from the leading edge. A thin sheet of polymide $\left(125 \mu \mathrm{m}\right.$ thickness, relative permittivity $\mathcal{\varepsilon}^{\prime} \approx 3$ ) was used as the dielectric barrier of the plasma actuator. As for the electrodes, thin sheets of copper (thickness $=35 \mu \mathrm{m}$ ) were glued and pressed onto the both sides of the dielectric. A high voltage, high-frequency power supply (PG1040F, PSI Inc.), which can output bipolar sinusoidal waveforms, was used to supply input signals to the top and bottom electrodes. The bottom electrode was connected to ground, $V_{g}=0 \mathrm{~V}$. The amplitude of input voltage to the top electrode $V_{\mathrm{AC}}$ was varied from $2.0 \mathrm{kV}$ to $2.8 \mathrm{kV}\left(4.0-5.6 \mathrm{kV}_{p-p}\right)$. The frequency of input voltage $f_{p}$ was fixed at $f_{p}=8.1 \mathrm{kHz}$.

\section{Results and Discussion}

3.1. Instantaneous Absolute Velocity Distributions. Figure 5 shows a sample of the PIV images, the instantaneous absolute velocity, and vorticity distributions for the baseline condition (plasma actuator off). Massive flow separation is visualized in the flow deceleration region in the PIV image of Figure 5(a). The large low-velocity region, drawn by blue contours in Figure 5(b), corresponds to the flow separation. (The criteria for separation or reattachment of the boundary layer are based on the boundary layer shape factor $H_{12}$, as shown in Figure 15 later). The separated boundary layer is stable from the streamwise location $x=20 \mathrm{~mm}$ (starting position of the flow separation) to $x=70 \mathrm{~mm}$ (namely $70 \%$ chord length position). The separated flow downstream of $x$ $=70 \mathrm{~mm}$ becomes unstable and large clockwise vortices are generated.

Figure 6 shows a sample of the PIV images, the instantaneous absolute velocity and vorticity distributions for the flow control condition (plasma actuator on, input voltage $V_{\mathrm{AC}}= \pm 2.8 \mathrm{kV}$, maximum input voltage in this study). The separated flow region is dramatically reduced by flow control using the plasma actuator. The flow separation from $x=$ $20 \mathrm{~mm}$ became unstable after $x=40 \mathrm{~mm} \sim 50 \mathrm{~mm}$ and small clockwise vortices were generated. The similar phenomenon of the smaller flow structure by the effect of the plasma actuator was observed in the flow visualization by Marks et al. [18]. The flow control using plasma actuator results in attached flow before the trailing edge.

3.2. Time-Averaged Absolute Velocity Distributions. Figure 7 shows enlarged views of the time-averaged absolute velocity

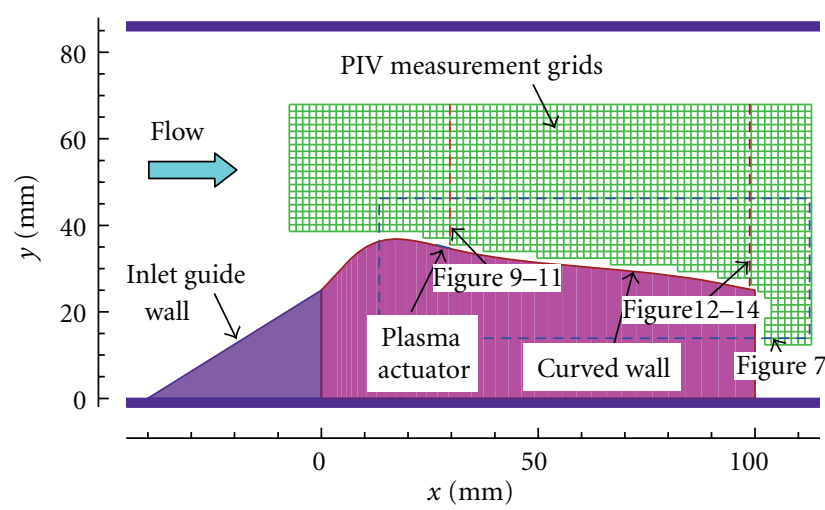

Figure 4: Test section and PIV grids.

distributions in the separation region (blue dashed frame in Figure 4) at various input voltages. These distributions were calculated by averaging 50 instantaneous velocity distributions as shown in Figures 5 and 6. In these figures, streamlines were superimposed upon the velocity contours.

The large separation region observed in the baseline (actuator off) condition in Figure 7(a) is gradually reduced by the effect of active control in Figures 7(b), 7(c), 7(d), 7(e), and $7(\mathrm{f})$.

In the baseline condition in Figure 7(a), large reverse flow is observed in the separation region. In the flow control case of $V_{\mathrm{AC}}= \pm 2.0 \mathrm{kV}$ in Figure 6(b), a large recirculation exists in the separation region, and the low-velocity region is slightly reduced near the trailing edge. In the flow control case of $V_{\mathrm{AC}}= \pm 2.2 \mathrm{kV}$ in Figure 6(c), the recirculation in the separation region become reduced in size and the position of its center moves upstream. The separated flow reattaches onto the surface of the curved wall before the trailing edge. In Figures 6(d), 6(e), and 6(f), at $V_{\mathrm{AC}}= \pm 2.4 \mathrm{kV} \pm 2.8 \mathrm{kV}$, as the input voltage is increased, the recirculation in the separation region become smaller and moves more upstream. The reduction of the separation region was observed in the LDV measurements by Huang et al. [13], the PIV measurements by Boxx et al. [16], total pressure measurements by Burman et al. [17], and the surface pressure measurements by Marks et al. [18].

3.3. Turbulence Intensity Distributions. Figure 8 shows turbulence intensity distributions at various input voltages. In these figures, velocity vectors were superimposed upon the turbulence intensity contours. The turbulence intensity was calculated as follows:

$$
\mathrm{Tu}=\frac{\sqrt{\left(u_{x}^{\prime 2}+u_{y}^{\prime 2}\right) / 2}}{U_{x, \text { main flow }}} .
$$

The turbulence intensity was normalized by the averaged streamwise velocity of the main flow near the trailing edge at $x=99.1 \mathrm{~mm}, U_{x \text {, main flow }} \approx 2.25 \mathrm{~m} / \mathrm{s}$, as shown in Figure 11 later.

In the baseline condition in Figure 8(a), a high turbulence intensity region exists at the boundary line between 


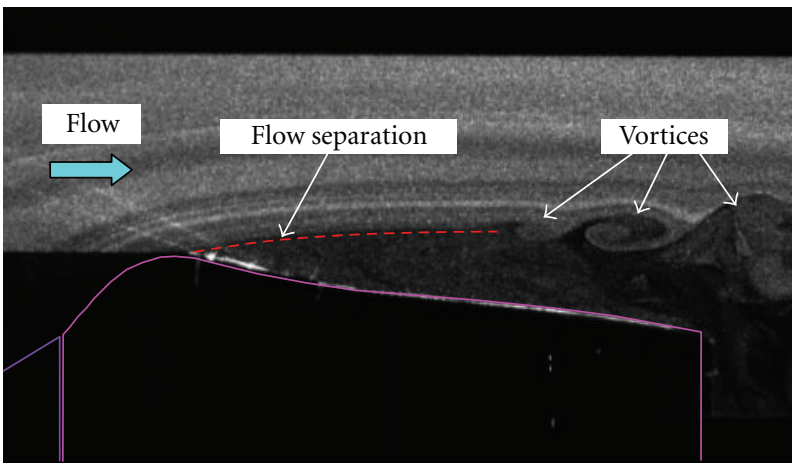

(a) PIV image

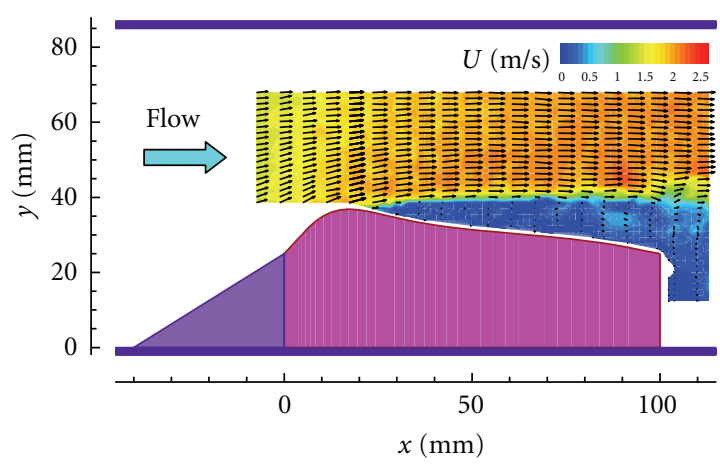

(b) Instantaneous absolute velocity

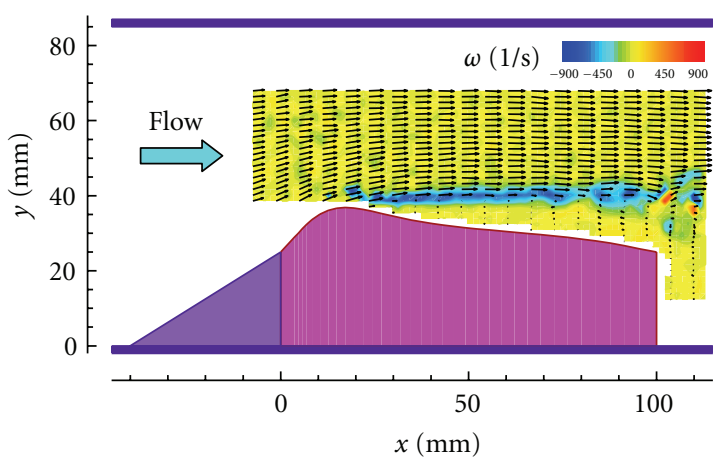

(c) Vorticity

Figure 5: PIV measurements (baseline, plasma actuator off).

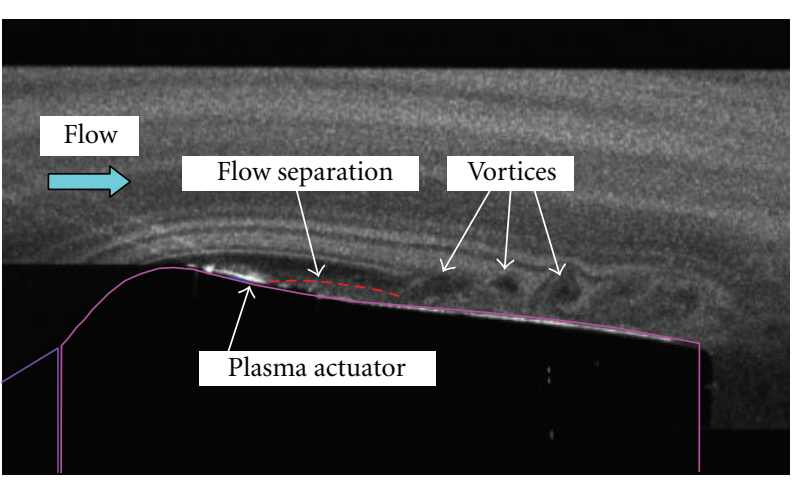

(a) PIV image

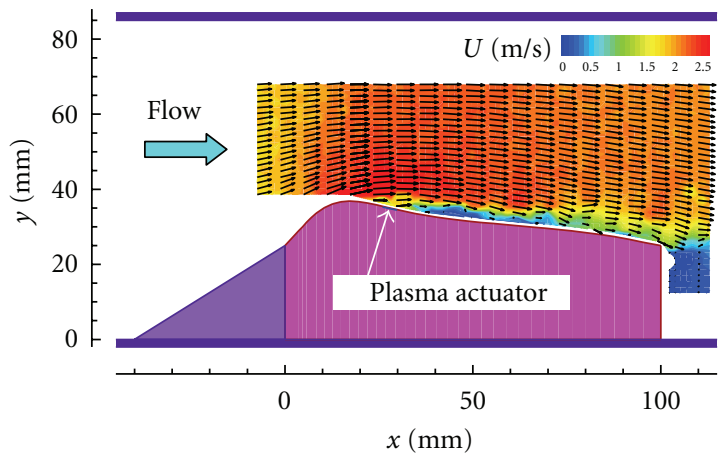

(b) Instantaneous absolute velocity

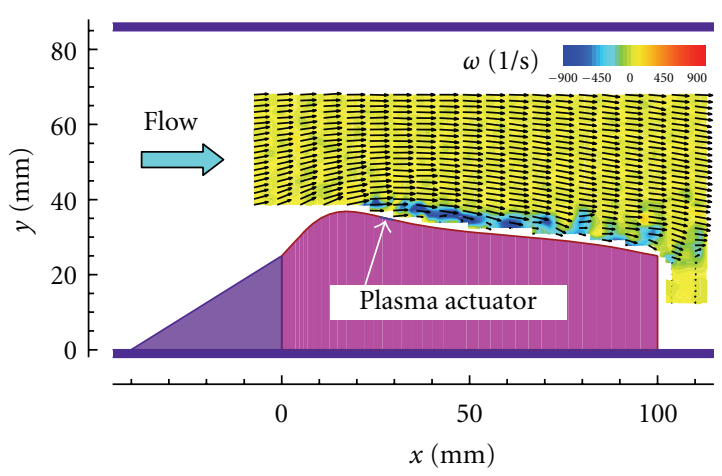

(c) Vorticity

FIGURE 6: PIV measurements (flow control, $V_{\mathrm{AC}}= \pm 2.8 \mathrm{kV}$ ). 


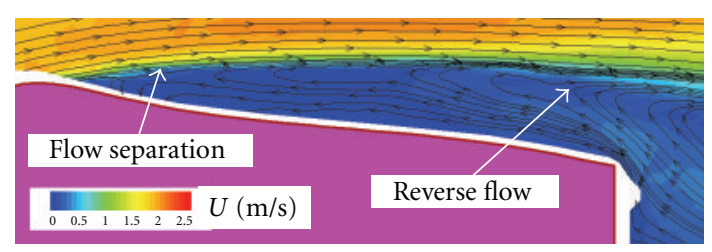

(a) Baseline

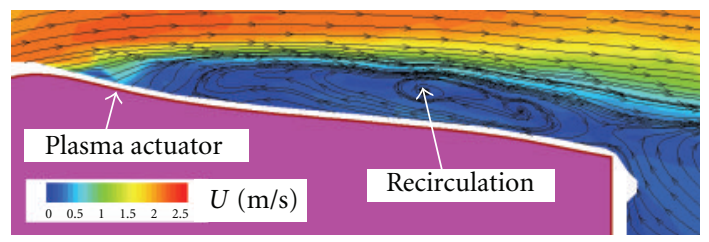

(b) Flow control $\left(V_{\mathrm{AC}}= \pm 2 \mathrm{kV}\right)$

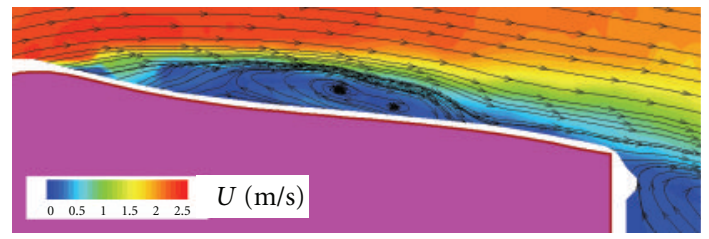

(c) Flow control $\left(V_{\mathrm{AC}}= \pm 2.2 \mathrm{kV}\right)$

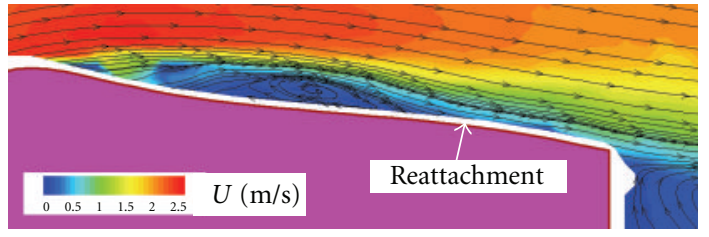

(d) Flow control $\left(V_{\mathrm{AC}}= \pm 2.4 \mathrm{kV}\right)$

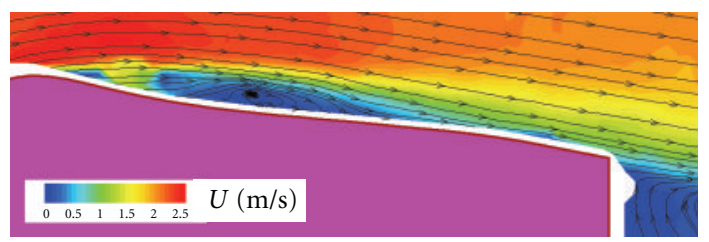

(e) Flow control $\left(V_{\mathrm{AC}}= \pm 2.6 \mathrm{kV}\right)$

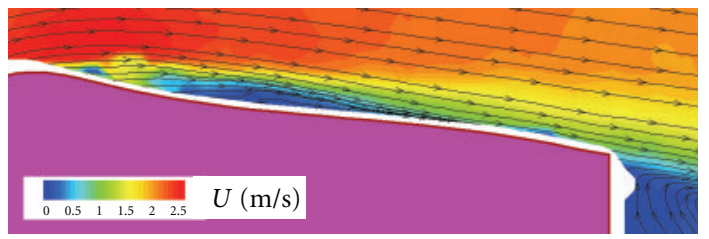

(f) Flow control $\left(V_{\mathrm{AC}}= \pm 2.8 \mathrm{kV}\right)$

FIGURE 7: Time-averaged absolute velocity distributions and stream lines near curved wall at various DBD-PA input voltages.

the main flow and the separated flow. A wide high turbulence intensity region is suddenly generated after $x=70 \mathrm{~mm}$. This phenomenon corresponds to the fact that the separated boundary layer is stable from $x=20 \mathrm{~mm}$ to $x=70 \mathrm{~mm}$ and becomes unstable after $x=70 \mathrm{~mm}$, as shown in Figure 5. The wide high turbulence intensity region after $x=70 \mathrm{~mm}$ is due to the unstable transitional separated boundary layer.

In the flow control case of $V_{\mathrm{AC}}= \pm 2.0 \mathrm{kV}$ in Figure 8(b), the high turbulence intensity region is generated after $x$ $=50 \mathrm{~mm}$, which is further upstream than the baseline condition.

In the flow control case of $V_{\mathrm{AC}}= \pm 2.2 \mathrm{kV}$ in Figure 8(c), the high turbulence intensity region moves even further upstream and closer to the curved wall than that in $V_{\mathrm{AC}}=$ $\pm 2.0 \mathrm{kV}$ condition, Figure $8(\mathrm{~b})$.

In Figures 8(c), 8(d), 8(e), and 8(f), as the input voltage is increased, the high turbulence intensity region moves more upstream and closer to the curved wall and becomes smaller in width.

\subsection{Velocity Distributions Around Plasma Actuator. Figure 9} shows the vertical distribution of the streamwise velocity $U_{x}$ near the center of the plasma actuator, $x=29.7 \mathrm{~mm}, x / L=$ 0.297 (red dashed line in Figure 4). The vertical position $y=34.6 \mathrm{~mm}$ corresponds to the surface of the curved wall. In the baseline condition (black line in the figure), the average streamwise velocity of the main flow is $2.05 \mathrm{~m} / \mathrm{s}$. The streamwise velocity in the boundary layer at $y \leq 40 \mathrm{~mm}$ is close to zero due to the flow separation near the curved wall. At $V_{\mathrm{AC}}= \pm 2.0 \mathrm{kV}$ (red line), the average streamwise velocity of the main flow increases to $2.26 \mathrm{~m} / \mathrm{s}(10 \%$ increase from the baseline condition). The streamwise velocity in the boundary layer increases to $0.73 \mathrm{~m} / \mathrm{s}$. At $V_{\mathrm{AC}}= \pm 2.2 \mathrm{kV}$ (pink), the average streamwise velocity of the main flow increases to $2.48 \mathrm{~m} / \mathrm{s}$ ( $21 \%$ increase from the baseline) and that in the boundary layer increases to $0.89 \mathrm{~m} / \mathrm{s}$. At $V_{\mathrm{AC}}= \pm 2.4 \mathrm{kV}$ (orange), the average streamwise velocity of the main flow increases slightly to $2.51 \mathrm{~m} / \mathrm{s}$ and that in the boundary layer increases to $1.27 \mathrm{~m} / \mathrm{s}$. At maximum input voltage of $V_{\mathrm{AC}}=$ $\pm 2.8 \mathrm{kV}$ (blue), the average streamwise velocity of the main flow increases to $2.58 \mathrm{~m} / \mathrm{s}$ (26\% increase from the baseline) and that in the boundary layer increases to $1.66 \mathrm{~m} / \mathrm{s}$.

Figure 10 shows the vertical distribution of the vertical velocity $U_{y}$ near the plasma actuator. The positive value means upward flow in the $y$-direction and the negative value means downward flow.

In the baseline condition (black line), the vertical velocity of the main flow at $y=42 \mathrm{~mm}$ is $0.27 \mathrm{~m} / \mathrm{s}$. As the input voltage is increased, the vertical velocity of the main flow is gradually reduced by the effect of active flow control of the plasma actuator. At maximum voltage of $V_{\mathrm{AC}}= \pm 2.8 \mathrm{kV}$ (blue), the vertical velocity of the main flow at $y=40 \mathrm{~mm}$ becomes $-0.07 \mathrm{~m} / \mathrm{s}(0.34 \mathrm{~m} / \mathrm{s}$ decrease from the baseline condition).

The vertical velocity of the boundary layer at $y \leq 40 \mathrm{~mm}$ is almost zero in the baseline condition. At $V_{\mathrm{AC}}= \pm 2.0 \mathrm{kV}$ (red line), the vertical velocity in the boundary layer increases to $0.3 \mathrm{~m} / \mathrm{s}$ due to the induced flow by the plasma actuator. As the input voltage is increased, the vertical velocity in the boundary layer is gradually reduced.

Figure 11 shows the vertical distribution of the flow angle $\theta$ near the plasma actuator. The positive value means upward flow and the negative value means downward flow. As the input voltage is increased, the flow angle in both the main flow and in the boundary layer is gradually reduced by 


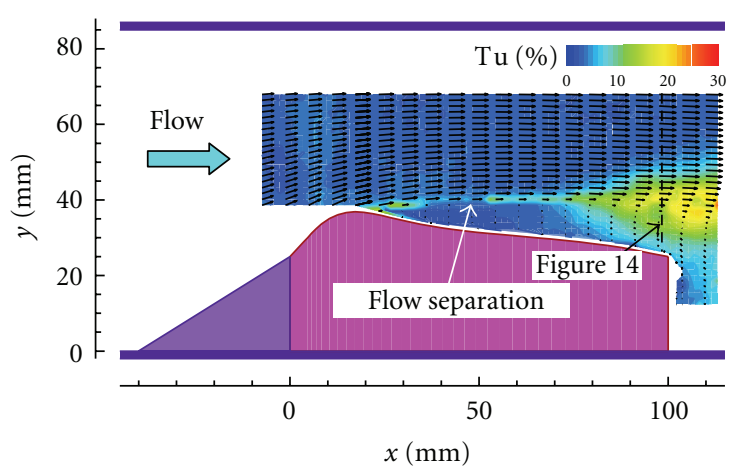

(a) Baseline

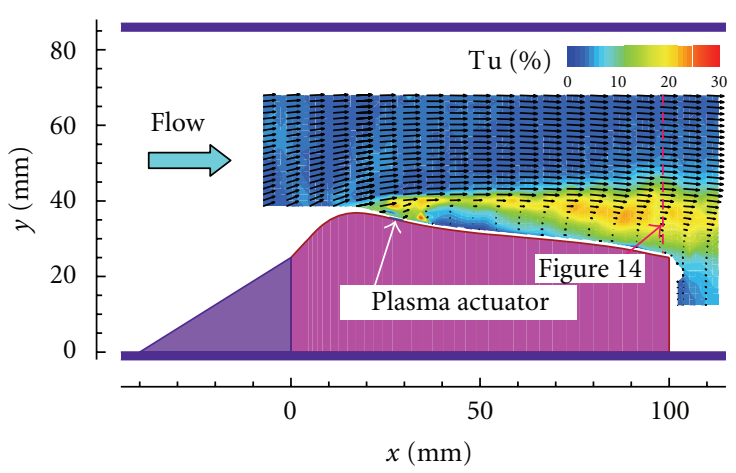

(b) Flow control $\left(V_{\mathrm{AC}}= \pm 2 \mathrm{kV}\right)$

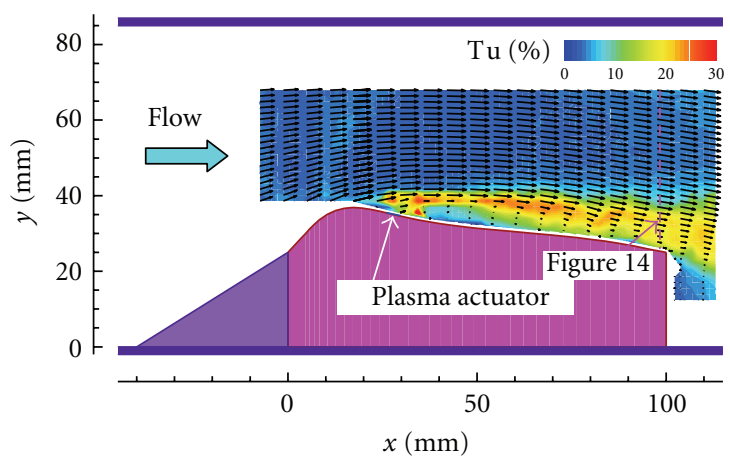

(c) Flow control $\left(V_{\mathrm{AC}}= \pm 2.2 \mathrm{kV}\right)$

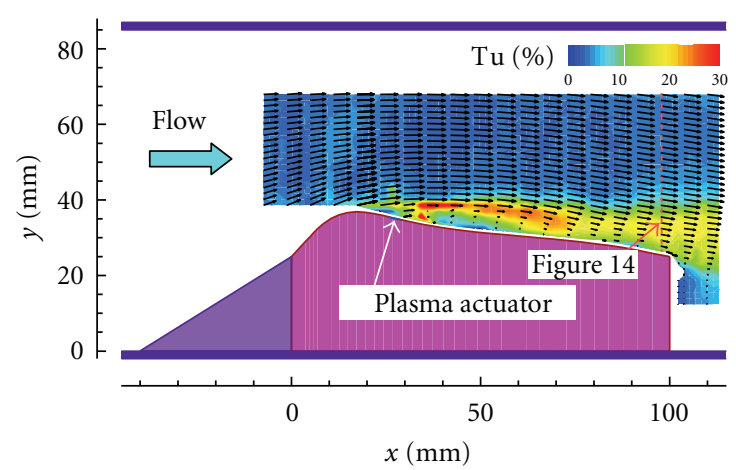

(d) Flow control $\left(V_{\mathrm{AC}}= \pm 2.4 \mathrm{kV}\right)$

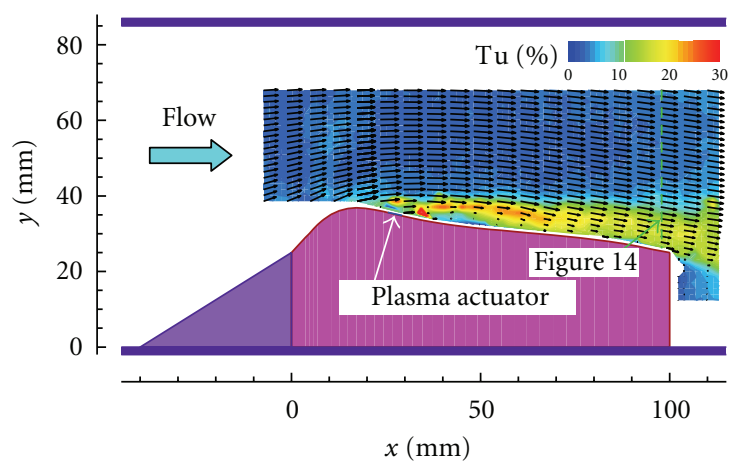

(e) Flow control $\left(V_{\mathrm{AC}}= \pm 2.6 \mathrm{kV}\right)$

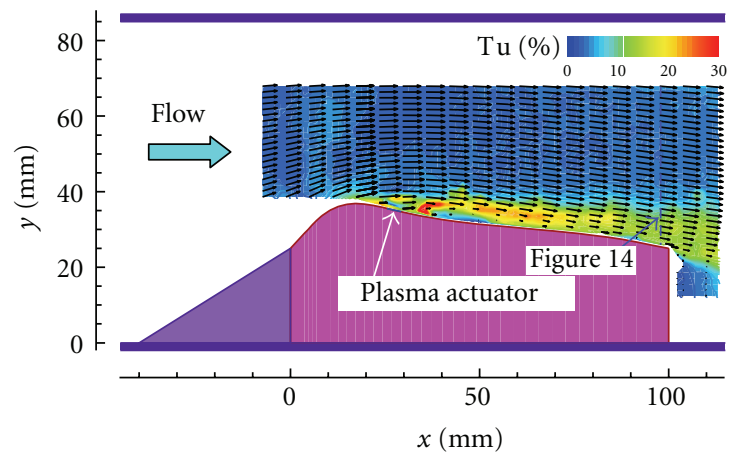

(f) Flow control $\left(V_{\mathrm{AC}}= \pm 2.8 \mathrm{kV}\right)$

FIGURE 8: Turbulence intensity distributions at various DBD-PA input voltages.

the effect of active flow control of the plasma actuator (i.e., decrease in separation angle). At $V_{\mathrm{AC}}= \pm 2.8 \mathrm{kV}$, the flow angle is reduced $9 \mathrm{deg}$ in the main flow and $23 \mathrm{deg}$ in the boundary layer, respectively.

3.5. Velocity Distributions Near Trailing Edge. Figure 12 shows the vertical distribution of the streamwise velocity near the trailing edge, $x=99.1 \mathrm{~mm}, x / L=0.991$ (brown dashed line in Figure 4). The bottom of the vertical axis (vertical position $y=25 \mathrm{~mm}$ ) corresponds to the surface of the curved wall at the trailing edge. The streamwise velocity of the main flow is almost constant $\left(U_{x \text {,main flow }} \approx 2.25 \mathrm{~m} / \mathrm{s}\right.$ ) for all input voltage conditions. In the baseline condition (black line in the figure), large velocity deficit with reverse flow exists near the surface of the curved wall. The boundary layer thickness (distance between the curved wall surface and the vertical position with $99 \%$ of the main flow velocity) is approximately $21 \mathrm{~mm}$ (from $x=25 \mathrm{~mm}$ to $x=46 \mathrm{~mm}$ ). At $V_{\mathrm{AC}}= \pm 2.0 \mathrm{kV}$ (red line), the reverse flow is reduced but the boundary layer thickness is the same as the baseline. At $V_{\mathrm{AC}}= \pm 2.2 \mathrm{kV}$ (pink), the velocity in the boundary layer is suddenly increased. The reverse flow region completely disappears and the boundary layer thickness is reduced to $17 \mathrm{~mm}$. At $V_{\mathrm{AC}}= \pm 2.4 \mathrm{kV}$ (orange), the shape of the velocity distributions in the boundary layer becomes quite linear. At $V_{\mathrm{AC}}= \pm 2.6 \mathrm{kV}$ and $V_{\mathrm{AC}}= \pm 2.8 \mathrm{kV}$ (green and blue), the velocity distributions in the boundary layer is further improved and the shape becomes convex. 


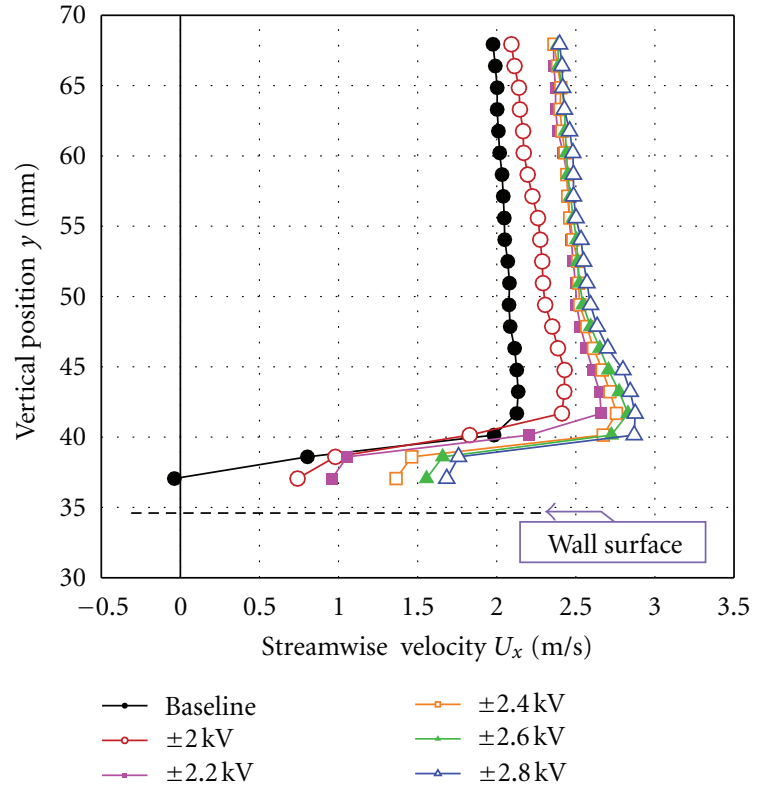

FIGURE 9: Streamwise velocity distributions near plasma actuator $(x=29.7 \mathrm{~mm})$.

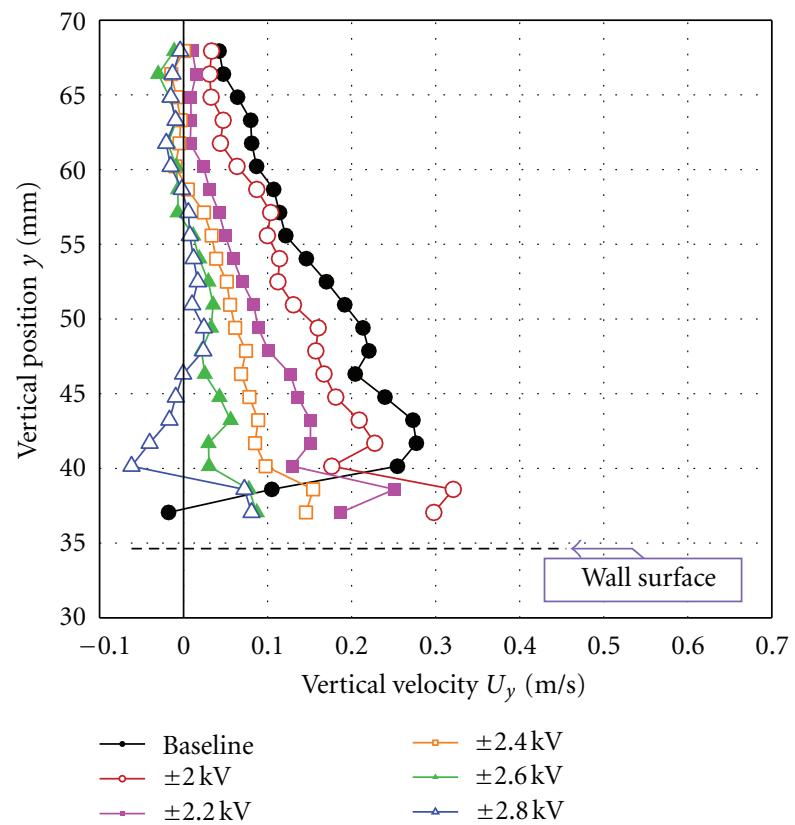

FIGURE 10: Vertical velocity distributions near plasma actuator $(x=$ $29.7 \mathrm{~mm}$ )

Figure 13 shows vertical distributions of the vertical velocity $U_{y}$ near the trailing edge, $x=99.1 \mathrm{~mm}$. As the input voltage is increased, the vertical velocity in both the main flow and in the boundary layer is reduced (maximum $0.42 \mathrm{~m} / \mathrm{s}$ reduction at $V_{\mathrm{AC}}= \pm 2.8 \mathrm{kV}$ ).

Figure 14 shows vertical distributions of the turbulence intensity near the trailing edge, $x=99.1 \mathrm{~mm}$ (dashed lines in Figure 8). Although the turbulence intensity of the main flow at the baseline is $2.1 \%$ for the baseline, that of the flow

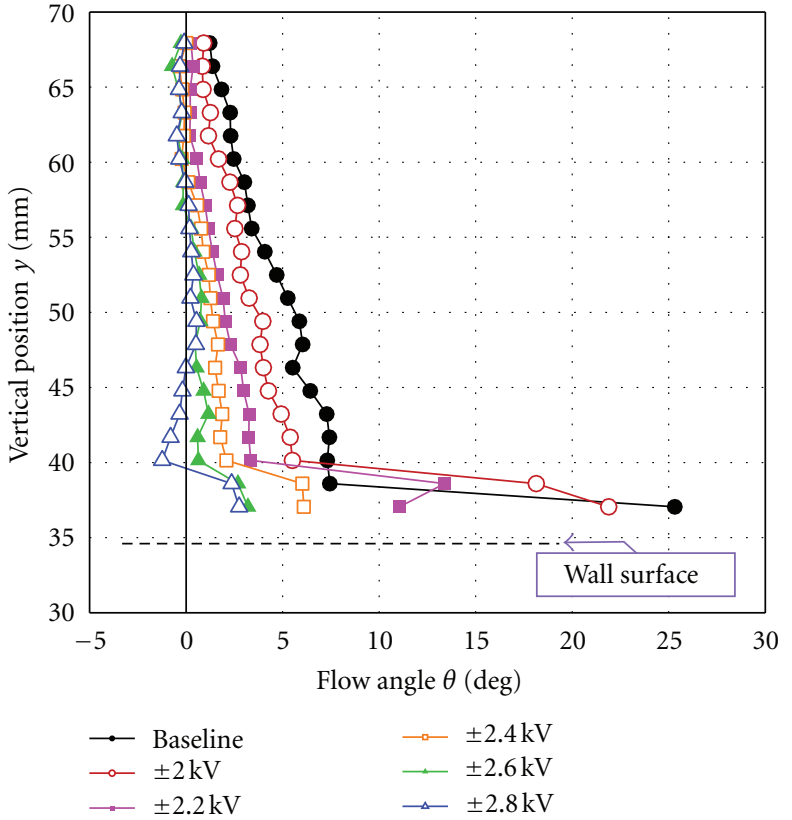

Figure 11: Flow angle distributions near plasma actuator $(x=$ $29.7 \mathrm{~mm}$ ).

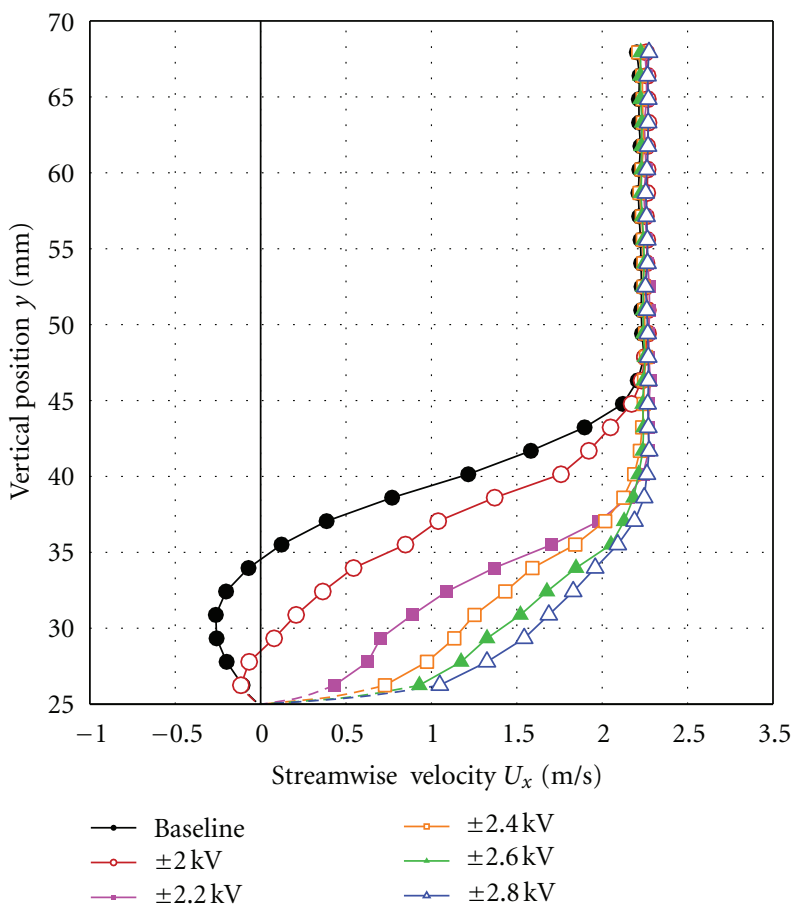

FIGURE 12: Streamwise velocity distributions near trailing edge ( $x=$ $99.1 \mathrm{~mm})$.

control conditions increase to $2.8 \%$ at $V_{\mathrm{AC}}= \pm 2.2 \mathrm{kV}$ and to $3.7 \% \sim 3.9 \%$ at $V_{\mathrm{AC}}= \pm 2.4 \mathrm{kV} \sim 2.8 \mathrm{kV}$. The slight increase in the turbulence intensity of the main flow is due to the flow fluctuation generated by the plasma actuator AC operation. In the baseline condition, the maximum turbulence intensity in the boundary layer is $17.5 \%$. The maximum turbulence 


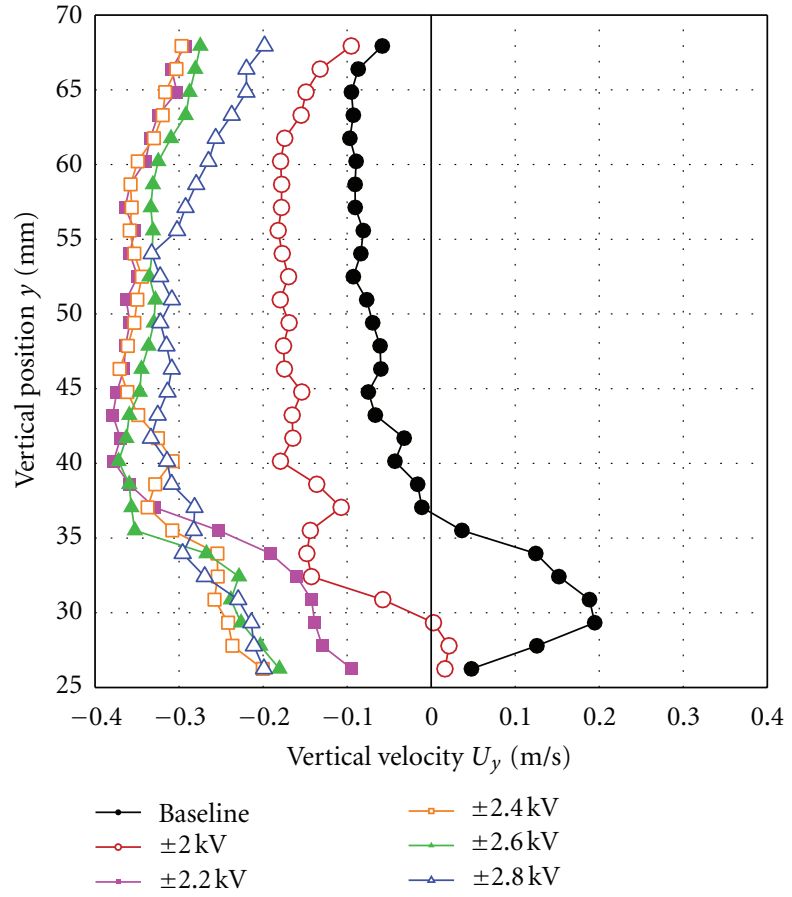

FIGURE 13: Vertical velocity distributions near trailing edge $(x=$ $99.1 \mathrm{~mm})$.

intensity increases to $20 \%$ at $V_{\mathrm{AC}}= \pm 2.0 \mathrm{kV} \sim 2.4 \mathrm{kV}$, and decreases to $16 \%$ and $14 \%$ at $V_{\mathrm{AC}}= \pm 2.6 \mathrm{kV}$ at $V_{\mathrm{AC}}=$ $\pm 2.8 \mathrm{kV}$, respectively. As the input voltage is increased, the vertical location of the maximum turbulence intensity moves closer to the wall, suggesting reattachment of the separated boundary layer. The similar phenomenon of the turbulence intensity change by the effect of the plasma actuator was observed in the PIV measurements by Boxx et al. [16].

3.6. Boundary Layer Displacement Thickness and Momentum Thickness at Trailing Edge. Figure 15 shows the displacement thickness, $\delta_{1}$, of the boundary layer near the trailing edge. The displacement thickness decreased by $20 \%$ at $\pm 2.0 \mathrm{kV}$. The displacement thickness is suddenly reduced as much as $56 \%$ at $\pm 2.2 \mathrm{kV}$, and it is reduced gradually from $\pm 2.4 \mathrm{kV}$ to $\pm 2.8 \mathrm{kV}$ (77\% reduction).

Figure 16 shows the momentum thickness, $\delta_{2}$, of the boundary layer near the trailing edge. The momentum thickness is $2.45 \mathrm{~mm}$ at the baseline condition. The momentum thickness slightly increases to $2.61 \mathrm{~mm}$ (6.5\% rise) at $V_{\mathrm{AC}}= \pm 2.4 \mathrm{kV}$, where the shape of boundary layer velocity is a straight line, as shown in Figure 12. The momentum thickness then decreases to $1.95 \mathrm{~mm}$ (20.4\% reduction) at $V_{\mathrm{AC}}= \pm 2.8 \mathrm{kV}$.

3.7. Boundary Layer Shape Factor at Trailing Edge. Figure 17 shows the boundary layer shape factor $H_{12}\left(=\delta_{1} / \delta_{2}\right)$ near the trailing edge. The shape factor $H_{12}$ is 6.40 at the baseline condition and reduces as the amplitude of input voltage increases.

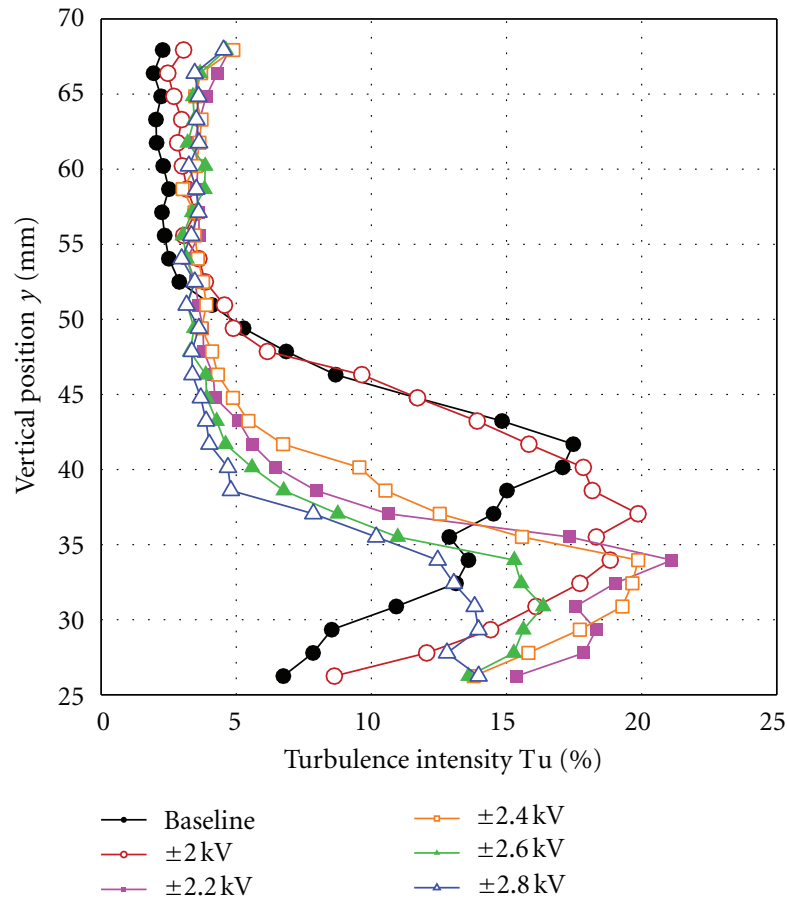

FIGURE 14: Turbulence intensity distributions near trailing edge ( $x=$ $99.1 \mathrm{~mm})$.

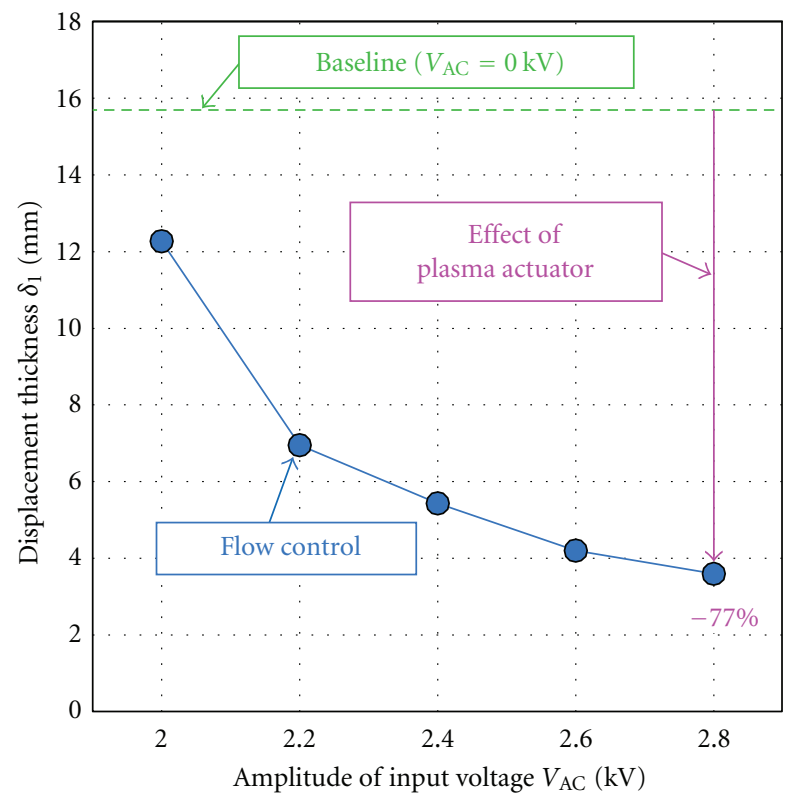

FIGURE 15: Displacement thickness of boundary layer near trailing edge $(x=99.1 \mathrm{~mm})$.

An empirical single-variable correlation using $H_{12}$ was developed for incipient and full detachment and for reattachment of turbulent boundary layers on two-dimensional surfaces [23]. The $H_{12}$ criteria of the correlation are $H_{12} \geq$ 4.0 for separated region (full detachment), $2.2 \leq H_{12} \leq 4.0$ for intermittent detachment, and $H_{12} \leq 2.2$ for attached boundary layer (reattachment). 


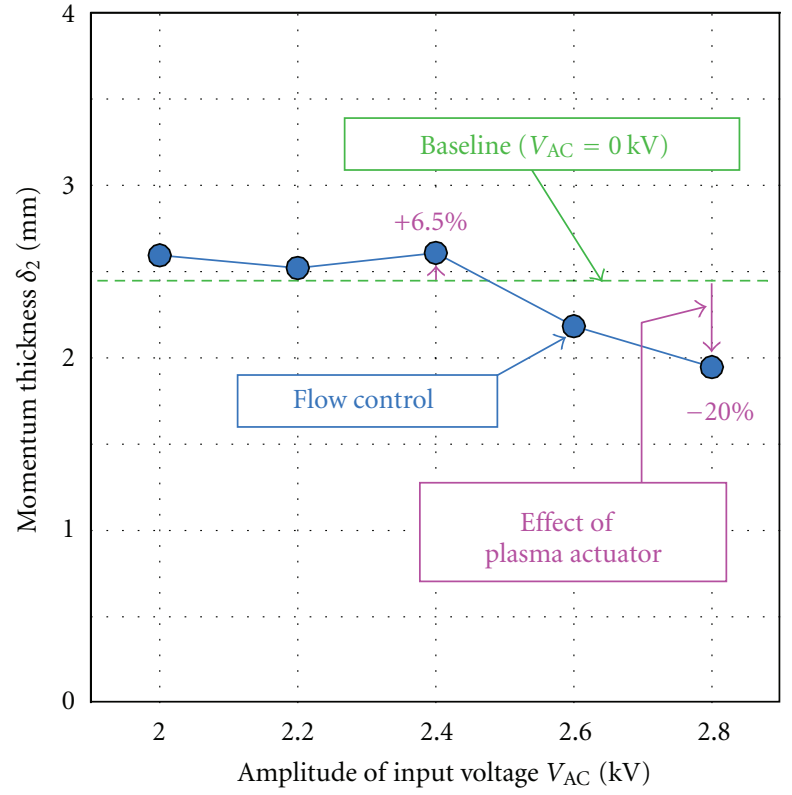

Figure 16: Momentum thickness of boundary layer near trailing edge $(x=99.1 \mathrm{~mm})$.

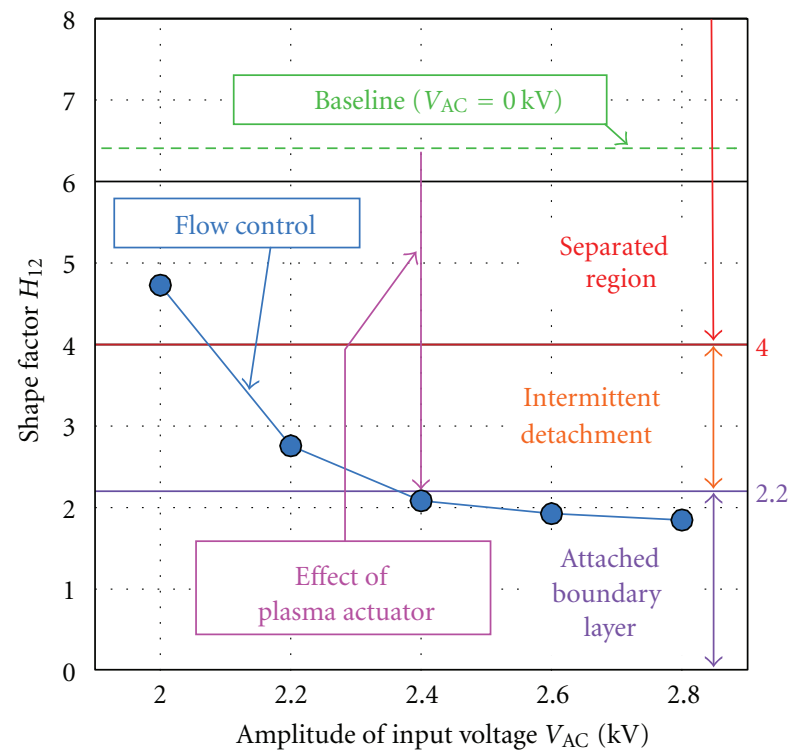

Figure 17: Shape factor $H_{12}$ near trailing edge $(x=99.1 \mathrm{~mm})$.

From the correlation, the boundary layer at baseline and $V_{\mathrm{AC}}= \pm 2.0 \mathrm{kV}$ is separated, that at $V_{\mathrm{AC}}= \pm 2.2$ is intermittently detached, and that at $V_{\mathrm{AC}}= \pm 2.4, \pm 2.6$ and $\pm 2.8 \mathrm{kV}$ is reattached.

3.8. Total Pressure Loss Estimation. Figure 18 shows total pressure loss estimation. The total pressure loss coefficient, $C_{P t}$, was estimated from the boundary layer displacement thickness, $\delta_{1}$, and momentum thickness, $\delta_{2}$, using the following correlation [24]:

$$
C_{P t}=\left(\frac{\delta_{1}+t}{w}\right)^{2}+\frac{2 \delta_{2}}{w}-\frac{C_{p b}}{w},
$$

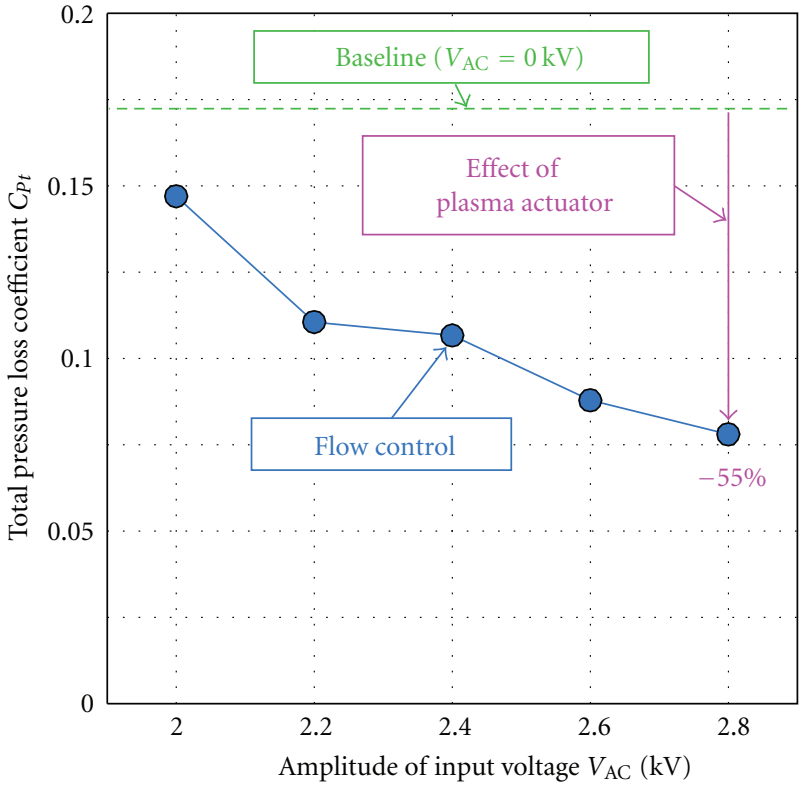

FIGURE 18: Total pressure loss estimation.

where $w$ is passage width $(60 \mathrm{~mm}), t$ is trailing edge thickness $(1.9 \mathrm{~mm})$, and $C_{p b}$ is base pressure coefficient. Because the $C_{p b}$ value is unknown in this study, the typical value of $C_{p b}=$ -0.15 is used for this estimation. The third term including $C_{p b}$ is about 3 6\% of $C_{P t}$; therefore, the effect of unknown $C_{p b}$ value is considered to be relatively smaller than the first and second terms.

The total pressure loss coefficient is 0.172 at the baseline condition. The total pressure loss is reduced to 0.107 (38\% reduction) at $\pm 2.2 \mathrm{kV}$, and 0.078 ( $55 \%$ reduction) at $\pm 2.8 \mathrm{kV}$.

\section{Conclusions}

Active flow control using dielectric barrier discharge plasma actuators was investigated to reattach the simulated separation flow over the suction surface of a turbine blade at low Reynolds number, $\operatorname{Re}=1.7 \times 10^{4}$. The flow separation was induced on a curved plate installed in the test section of a low-speed wind tunnel. Particle image velocimetry (PIV) was used to obtain instantaneous and time-averaged twodimensional velocity measurements. The amplitude of input voltage for the plasma actuator was varied from $\pm 2.0 \mathrm{kV}$ to $\pm 2.8 \mathrm{kV}$. Due to the flow control using the plasma actuator, the separated flow was successfully reduced. The decrease in displacement thickness of the boundary layer near the trailing edge was $20 \%$ at $\pm 2.0 \mathrm{kV}$. The displacement thickness was suddenly reduced by as much as $56 \%$ at $\pm 2.2 \mathrm{kV}$ and it was reduced gradually from $\pm 2.4 \mathrm{kV}$ to $\pm 2.8 \mathrm{kV}$ (77\% reduction). The total pressure loss coefficient, estimated from the boundary layer displacement thickness and momentum thickness, was 0.172 at the baseline condition. The total pressure loss coefficient was reduced to 0.107 ( $38 \%$ reduction) at $\pm 2.2 \mathrm{kV}$, and 0.078 (55\% reduction) at $\pm 2.8 \mathrm{kV}$. 


\section{Nomenclature}

\begin{tabular}{|c|c|}
\hline$C_{p b}:$ & $\begin{array}{l}\text { Base pressure coefficient, }-0.15 \text { (typical } \\
\text { value) }\end{array}$ \\
\hline$C_{P t}:$ & $\begin{array}{l}\text { Total pressure loss coefficient } C_{P t}= \\
\left(P t_{\text {in }}-P t_{\text {out }}\right) /\left((1 / 2) \rho U_{\text {out }}{ }^{2}\right)\end{array}$ \\
\hline$D:$ & Diffusion factor $D=1-\left(U_{\text {out }} / U_{\max }\right)$ \\
\hline$f_{p}:$ & Frequency of input voltage \\
\hline$H_{12}$ : & Shape factor $\left(=\delta_{1} / \delta_{2}\right)$ \\
\hline$L:$ & Streamwise length of curved wall, $100 \mathrm{~mm}$ \\
\hline$P t_{\text {in }}:$ & Total pressure at inlet \\
\hline$P t_{\text {out }}:$ & Mass-averaged total pressure at outlet \\
\hline Re: & Reynolds number \\
\hline Tu: & Turbulence intensity \\
\hline$t:$ & Trailing edge thickness, $1.9 \mathrm{~mm}$ \\
\hline$U:$ & Absolute velocity \\
\hline$U_{\text {out }}:$ & Mass-averaged absolute velocity at outlet \\
\hline$U_{\max }:$ & Maximum absolute velocity \\
\hline$U_{x}:$ & Streamwise velocity \\
\hline$U_{x \text {, main flow: }}$ : & $\begin{array}{l}\text { Averaged streamwise velocity of main flow } \\
\text { near trailing edge }\end{array}$ \\
\hline$u_{x}^{\prime}:$ & $\begin{array}{l}\text { Random fluctuation (turbulence) } \\
\text { component of streamwise velocity }\end{array}$ \\
\hline$U_{y}:$ & Vertical velocity \\
\hline$u_{y}^{\prime}:$ & $\begin{array}{l}\text { Random fluctuation (turbulence) } \\
\text { component of vertical velocity }\end{array}$ \\
\hline$V_{\mathrm{AC}}:$ & Amplitude of input voltage \\
\hline$w:$ & $\begin{array}{l}\text { Flow passage width at trailing edge, } \\
60 \mathrm{~mm}\end{array}$ \\
\hline$x:$ & Streamwise (horizontal) distance \\
\hline$y:$ & Vertical distance \\
\hline$\delta_{1}:$ & Boundary layer displacement thickness \\
\hline$\delta_{2}:$ & Boundary layer momentum thickness \\
\hline$\theta:$ & Flow angle \\
\hline$\rho:$ & Density. \\
\hline
\end{tabular}

\section{Acknowledgments}

This study was supported by Grant-in-Aid for Young Scientists (B) of KAKENHI (no. 20760124) from The Ministry of Education, Culture, Sports, Science and Technology (MEXT), Japan. The authors would like to sincerely thank Dr. Timothy Jukes of the University of Nottingham for his helpful advice.

\section{References}

[1] R. Sondergaard, R. B. Rivir, and J. P. Bons, "Control of lowpressure turbine separation using vortex-generator jets," Journal of Propulsion and Power, vol. 18, no. 4, pp. 889-895, 2002.

[2] H. Arakawa, T. Suzuki, K. Saito, S. Tamura, and S. Kishi, "Research and development of $300 \mathrm{~kW}$ class ceramic gas turbine project in Japan," ASME Paper 97-GT-87, 1997.

[3] C. G. Murawski, R. Sondergaard, R. B. Rivir, K. Vafai, T. W. Simon, and R. J. Volino, "Experimental study of the unsteady aerodynamics in a linear cascade with low reynolds number low pressure turbine blades,” ASME Paper 97-GT-95, 1997.

[4] W. Lou and J. Hourmouziadis, "Separation bubbles under steady and periodic-unsteady main flow conditions," ASME Journal of Turbomachinery, vol. 122, no. 4, pp. 634-643, 2000.
[5] R. J. Howell, O. N. Ramesh, H. P. Hodson, N. W. Harvey, and V. Schulte, "High lift and aft-loaded profiles for low-pressure turbines," ASME Journal of Turbomachinery, vol. 123, no. 2, pp. 181-188, 2001.

[6] R. J. Volino and L. S. Hultgren, "Measurements in separated and transitional boundary layers under low-pressure turbine airfoil conditions," ASME Journal of Turbomachinery, vol. 123, no. 2, pp. 189-197, 2001.

[7] K. W. Van Treuren, T. Simon, M. von Koller, A. R. Byerley, J. W. Baughn, and R. Rivir, "Measurements in a turbine cascade flow under ultra low reynolds number conditions," ASME Journal of Turbomachinery, vol. 124, no. 1, pp. 100-106, 2002.

[8] R. B. Rivir, R. Sondergaard, and J. P. Bons, "Control of separation in turbine boundary layers," AIAA Paper 2004-2201, 2004.

[9] J. R. Roth, D. M. Sherman, and S. P. Wilkinson, "Boundary layer flow control with a one atmosphere uniform grow discharge," AIAA Paper 98-0328, 1998.

[10] T. C. Corke, C. L. Enloe, and S. P. Wilkinson, "Dielectric barrier discharge plasma actuators for flow control," Annual Review of Fluid Mechanics, vol. 42, pp. 505-529, 2010.

[11] Y. B. Suzen and P. G. Huang, "Simulations of flow separation control using plasma actuators," AIAA Paper 2006-877, 2006.

[12] J. Huang, T. C. Corke, and F. O. Thomas, "Plasma actuators for separation control of low-pressure turbine blades," AIAA Paper 2003-1027, 2003.

[13] J. Huang, T. C. Corke, and F. O. Thomas, "Unsteady plasma actuators for separation control of low-pressure turbine blades," AIAA Journal, vol. 44, no. 7, pp. 1477-1487, 2006.

[14] D. P. Rizzetta and M. R. Visbal, "Numerical investigation of plasma-based flow control for a transitional highly-loaded low-pressure turbine,” AIAA Paper 2007-938, 2007.

[15] Y. B. Suzen, P. G. Huang, and D. E. Ashpis, "Numerical simulations of flow separation control in low-pressure turbines using plasma actuators," AIAA Paper 2007-937, 2007.

[16] I. G. Boxx, J. M. Newcamp, M. E. Franke, N. M. Woods, and R. B. Rivir, "A PIV study of a plasma discharge flow-control actuator on a flat plate in an aggressive pressure induced Separation," ASME Paper GT2006-91044, 2006.

[17] D. Burman, T. W. Simon, U. Kortshagen, and D. Ernie, "Separation control using plasma actuators: steady flow in low pressure turbines," ASME Paper GT-2011-46807, 2011.

[18] C. Marks, R. Sondergaard, and M. Wolff, "Experimental comparison of DBD plasma actuators for low reynolds number separation control," ASME Paper GT-2011-45397, 2011.

[19] T. Matsunuma, "Effects of Reynolds number and freestream turbulence on turbine tip clearance flow," ASME Journal of Turbomachinery, vol. 128, no. 1, pp. 166-177, 2006.

[20] T. Matsunuma, "Unsteady flow field of an axial-flow turbine rotor at a low Reynolds number," ASME Journal of Turbomachinery, vol. 129, no. 2, pp. 360-371, 2007.

[21] P. Magnier, D. Hong, A. Leroy-Chesneau, J. M. Bauchire, and J. Hureau, "Control of separated flows with the ionic wind generated by a DC corona discharge," Experiments in Fluids, vol. 42, no. 5, pp. 815-825, 2007.

[22] T. N. Jukes and K.-S. Choi, "Dielectric-barrier-discharge vortex generators: characterisation and optimisation for flow separation control," Experiments in Fluids, vol. 52, no. 2, pp. 329-345, 2012.

[23] S. J. Kline, J. G. Bardina, and R. C. Strawn, "Correlation of the detachment of two-dimensional turbulent boundary layers," AIAA Journal, vol. 21, no. 1, pp. 68-73, 1983.

[24] J. D. Denton, "Loss mechanisms in turbomachines," ASME Journal of Turbomachinery, vol. 115, no. 4, pp. 621-656, 1993. 

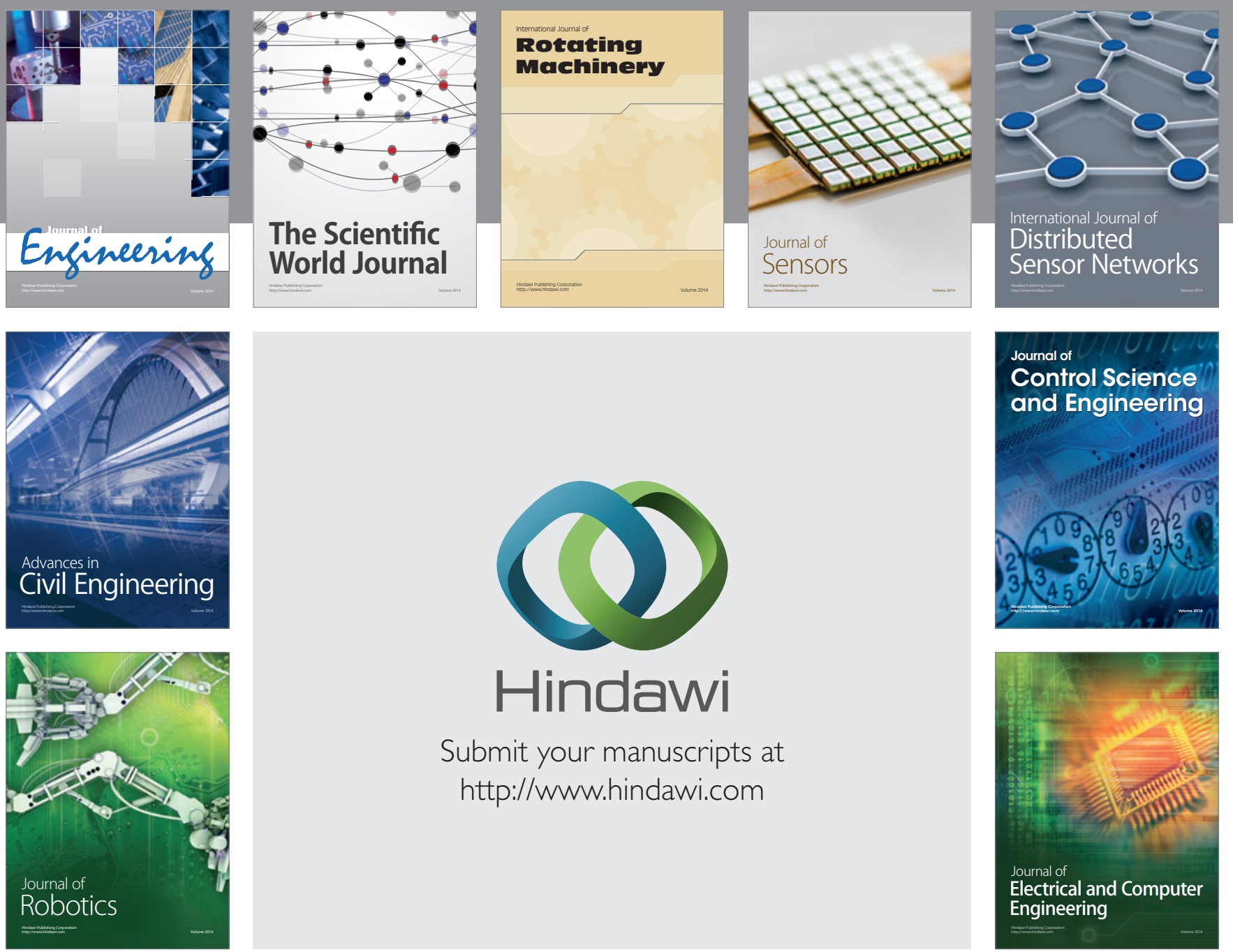

Submit your manuscripts at

http://www.hindawi.com
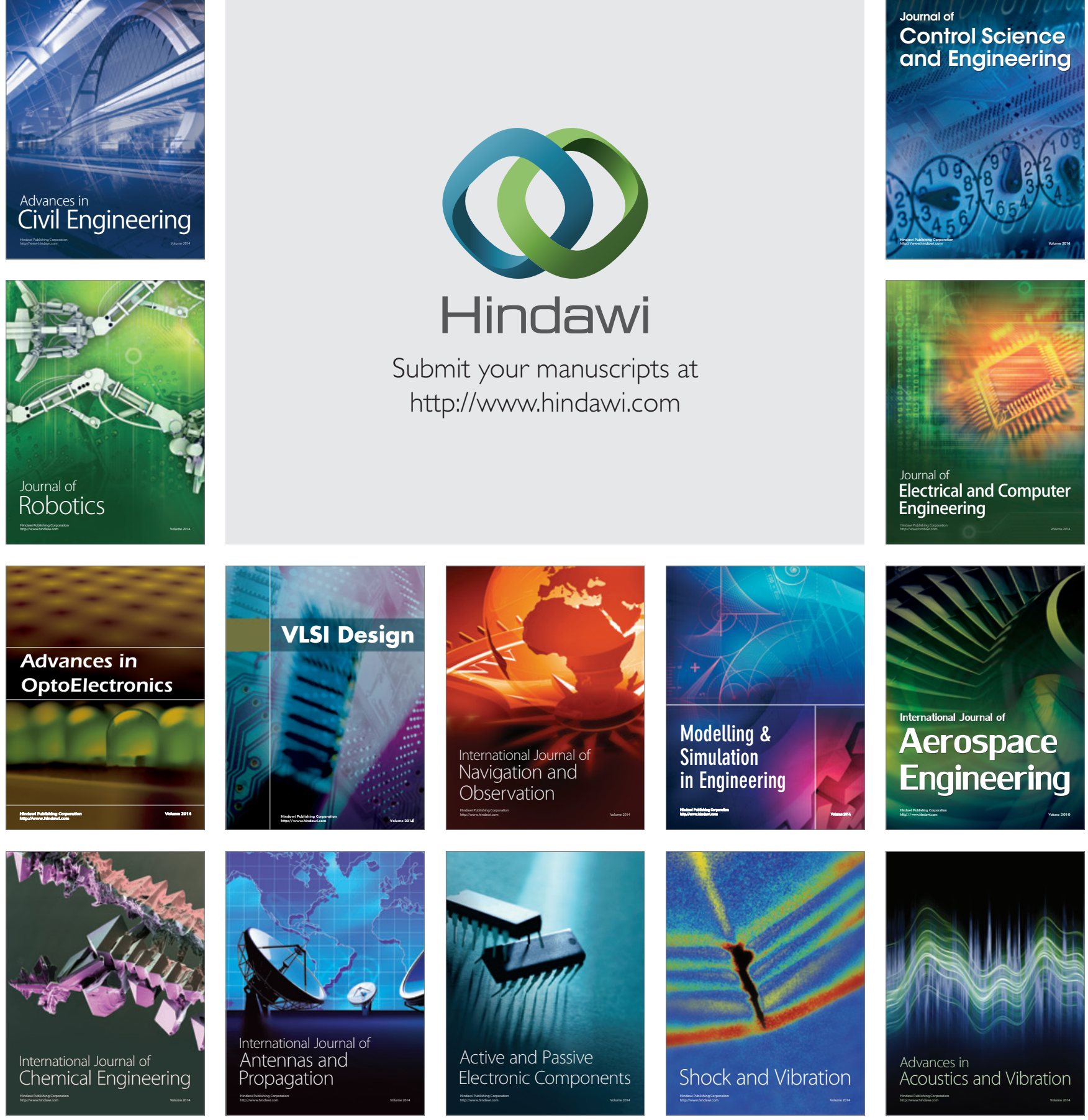